\title{
DESCRITORES QUALITATIVOS E MULTICATEGÓRICOS NA ESTIMATIVA DA VARIABILIDADE FENOTÍPICA ENTRE ACESSOS DE PIMENTAS
}

\section{QUALITATIVE AND MULTICATEGORICAL DESCRIPTORS IN THE ESTIMATION OF PHENOTYPIC VARIABILITY AMONG CHILI PEPPER ACCESSIONS}

\author{
Cíntia dos Santos BENTO ${ }^{1}$ \\ Cláudia Pombo SUDRE'2 \\ Rosana RODRIGUES ${ }^{3}$ \\ Elaine Manelli RIVA ${ }^{4}$ \\ Messias Gonzaga PEREIRA ${ }^{3}$
}

\begin{abstract}
RESUMO
O uso de germoplasma em programas de melhoramento está relacionado à disponibilidade de informações sobre os acessos contidos numa coleção ou banco. A caracterização e a divergência genética e fenotípica entre acessos de bancos de germoplasma têm sido determinadas, e várias espécies de hortaliças já foram objeto de estudos nessa área. Com o objetivo de quantificar a divergência fenotípica entre 29 acessos de Capsicum spp., com base em caracterização morfológica e agronômica, 37 descritores foram analisados utilizando-se técnicas de componentes principais, análise de agrupamento e variáveis multicategóricas. O experimento foi conduzido em condições de campo, em Campos dos Goytacazes, RJ, no período de março a dezembro de 2004. Os dados obtidos foram analisados utilizando-se os recursos computacionais do programa GENES. Os grupos formados pelos métodos de Tocher e do vizinho mais próximo foram parcialmente concordantes. A análise de variáveis multicategóricas foi eficiente na quantificação da divergência fenotípica.
\end{abstract}

Palavras-chave : recursos genéticos, variáveis multicategóricas, análise multivariada, Capsicumspp.

\begin{abstract}
The use of germplasm in breeding programs is related to the availability of information on the accessions of a collection or germplasm bank. The characterization and the quantification of genetic and phenotypic divergence among accessions were already studied, including many vegetables species. Aiming to quantify the phenotypic divergence among 29 Capsicum spp. accessions, based on morphological and agronomic traits, 37 descriptors were analyzed using principal components, cluster analysis and multicategorical variables. The experiment was carried out in field conditions, at Campos dos Goytacazes, RJ, from March to December, 2004. The data were analyzed using GENES software. The clusters formed using Tocher and nearest neighbor clustering methods showed partial agreement. The use of multicategorical analysis was efficient to quantify the phenotypic divergence.

Key-words : genetic resources, multicategorical analysis, multivariate analysis, chilli peppers, sweet peppers.
\end{abstract}

\footnotetext{
'Pós-Graduanda em Genética e Melhoramento de Plantas da Universidade Estadual do Norte Fluminense Darcy Ribeiro - UENF, Av. Alberto Lamego, 2000, Parque Califórnia, 28013-602, Campos dos Goytacazes-RJ, e-mail: cdossantosbento@yahoo.com.br. Autor para correspondência. ${ }^{2}$ Doutoranda em Genética e Melhoramento de Plantas da UENF, Eng.Agr., Técnica de nível superior;

${ }^{3}$ Engenheira Agrônoma, Doutora em Produção Vegetal, Professora Associada I da UENF.

${ }^{3}$ Engenheiro Agrônomo, Doutor em Produção Vegetal, Professor Associado I da UENF.

${ }^{4}$ Engenheira Agrônoma, Doutora em Produção Vegetal.
} 


\section{INTRODUÇÃO}

Os recursos genéticos são utilizados como fonte de variação genética para características desejáveis e necessárias para o melhoramento de plantas (RODRIGUEZ et al., 1999). Para estimar a diversidade fenotípica entre os acessos de um banco de germoplasma, é necessário que estes sejam caracterizados e avaliados (BUENO et al., 2001). Refere-se a distância fenotípica quando se utiliza a matriz de distância Euclidiana originada de dados sem repetição ou apenas uso de médias. A caracterização de germoplasma é importante, pois auxilia no conhecimento e no uso da variabilidade genética, permitindo aos melhoristas selecionar acessos para obtenção de populações e linhagens que atendam as necessidades específicas de um programa de melhoramento (CARVALHO et al., 2003).

A caracterização morfoagronômica deve considerar descritores botânicos de alta herdabilidade, fácil mensuração e pouca interação genótipo $x$ ambiente. Os aspectos morfológicos e fenológicos também devem ser observados de forma sistemática nos acessos, por meio de descritores, que são caracteres utilizados para descrever um acesso. Na avaliação de germoplasma, para maior confiabilidade dos dados, torna-se necessário o uso de um modelo experimental, que obedeça aos princípios básicos da experimentação agrícola (VALLS, 1988).

Técnicas de análises multivariadas têm sido empregadas para a quantificação da divergência genotípica e fenotípica em várias espécies de hortaliças (COSTA et al., 2006; RAMOS, 2006; SUDRÉ et al., 2005; ABREU et al., 2004; MARTINELLO et al., 2003; REGO et al., 2003). O estudo de divergência permite conhecer o grau de seleção da variabilidade genética das populações vegetais (AMARAL JR e THIÉBAUT, 1999), e também subsidia a seleção de genitores geneticamente mais divergentes, que poderão ser utilizados em intercruzamentos para se obter efeito heterótico na geração híbrida e aumentar a probabilidade de recuperação de segregantes superiores em gerações avançadas (CRUZ e REGAZZI, 2001).

As pimentas e os pimentões representam um importante mercado para a agricultura brasileira, incluindo o seu uso como matéria-prima para as indústrias alimentícia, farmacêutica e cosmética. A demanda por novas cultivares que associem qualidade, produtividade e resistência a pragas e doenças tem aumentado, sobretudo para atender ao processamento industrial. A variabilidade genética mantida em bancos de germoplasma é a base para obtenção de novas cultivares que vão permitir o atendimento a essa demanda. Dessa forma, a caracterização e a conservação dos recursos genéticos é de fundamental importância não só para a conservação da variabilidade, mas também para a disponibilidade de acessos a serem utilizados em programas de melhoramento (NASS e PATERNIANI, 2000; CARVALHO et al., 2003).
O aumento do uso de germoplasma em programas de melhoramento e por comunidades rurais está relacionado à disponibilidade de informações sobre os acessos mantidos nas coleções ou bancos, geradas a partir de estudos morfoagronômicos e de divergências genotípica e fenotípica, permitindo o maior conhecimento dos acessos preservados e a possibilidade de uma ampla utilização desses (SCHUELTER, 1996).

Este trabalho teve como objetivo quantificar a divergência fenotípica entre 29 acessos de Capsicum spp., com base em caracterização morfológica e agronômica, utilizando-se de 37 descritores sugeridos pelo IPGRI (1995), e técnicas de análise multivariada.

\section{MATERIAL E MÉTODOS}

Vinte e nove acessos de Capsicum spp., da coleção de germoplasma do Centro de Ciências e Tecnologias Agropecuárias da Universidade Estadual do Norte Fluminense Darcy Ribeiro, foram utilizados neste estudo. Esses acessos são provenientes de coletas realizadas em feiras e em áreas de produção de várias partes do Brasil (nove do Rio de Janeiro, dois do Espírito Santo, um da Bahia, três do Mato Grosso do Sul e 12 de Minas Gerais), intercâmbio entre pesquisadores (um dos Estados Unidos da América) e de cultivar comercial (Cambuci).

O experimento foi conduzido em condições de campo, em área de convênio da UENF com a Empresa de Pesquisa Agropecuária do Estado do Rio de Janeiro (PESAGRO-RIO), em Campos dos Goytacazes, RJ, no período de março a dezembro de 2004. A semeadura foi realizada em bandejas de isopor (poliestireno) de 128 células preenchidas com substrato orgânico. Foram avaliadas três plantas por acesso, no espaçamento de 1,0 m X 0,5 m.

$\mathrm{Na}$ caracterização morfoagronômica dos acessos foram utilizados 37 descritores, propostos pelo IPGRI (1995), sendo 15 quantitativos e 22 qualitativos. Nos descritores quantitativos de folha considerou-se a média de três folhas por planta de cada acesso e nos de fruto anotaram-se os dados de dez frutos por planta. Os descritores quantitativos estudados foram: comprimento da folha; largura da folha; altura da planta; maior diâmetro da copa; menor diâmetro da copa; área da copa da planta; dias para frutificação; comprimento do fruto; largura do fruto; espessura da polpa; número de frutos por planta; peso médio de frutos por planta; número de sementes por fruto; peso de sementes por fruto (em gramas); peso de mil sementes.

Nos caracteres qualitativos relacionados a folha os dados foram obtidos a partir da moda das observações tomadas em três folhas por planta, totalizando nove folhas por acesso. Foram considerados os seguintes descritores relacionados a folha: cor; forma; margem, e pubescência. Nos descritores qualitativos hábito de crescimento da planta; cor do caule; número de flores por axila; posição da flor; cor da corola, e cor das anteras, a 
moda foi obtida a partir da observação das três plantas de cada acesso.

Nos descritores relativos a fruto foram avaliados dez frutos por planta, totalizando 30 frutos por acesso. Os seguintes descritores foram avaliados: forma; presença ou ausência de ombro; forma do ápice; margem do cálice; cor no estádio intermediário (os frutos foram classificados pela última gradação de cores antes da fase de maturação); cor no estádio maduro; tipo de epiderme; constrição anular do cálice; constrição na base; rachaduras; número de lóculos e cor da semente.

As seguintes técnicas de análises multivariadas foram aplicadas aos dados quantitativos: análise de componentes principais; importância relativa das características, baseandose no método proposto por SINGH (1981); método de descarte de variáveis (GARCIA, 1998) que consiste na eliminação da variável com menor contribuição para divergência e reagrupamento dos acessos pelo método de Tocher, e assim sucessivamente até haver mudança na formação dos grupos; método de agrupamento do vizinho mais próximo; e método de otimização de Tocher (CRUZ e REGAZZI, 2001).

A técnica de componentes principais foi adotada porque se baseia apenas nas informações individuais de cada acesso, sem necessidade de dados com repetições (CRUZ e REGAZZI, 2001), tendo sido conduzidas três plantas por acesso e obteve-se a média destes indivíduos.

Posteriormente, visando complementar o estudo de divergência genética foi realizada a análise multicategórica entre 28 acessos, com base nos dados qualitativos. A matriz de dissimilaridade foi obtida a partir das modas oriundas de três plantas por acesso. Esta análise permitiu o agrupamento dos acessos pelo método Tocher.

Os dados obtidos, qualitativos e quantitativos, foram analisados utilizando-se os recursos computacionais do programa Genes, versão 2006 (CRUZ, 2006).

\section{RESULTADOS E DISCUSSÃO}

Houve diversidade fenotípica entre os acessos de Capsicum spp. estudados. Na análise dos componentes principais, os três primeiros componentes (Tabela 1), explicaram cerca de $80 \%$ da variância total, adequando-se, neste caso, a uma representação gráfica tridimensional (Figura 1).

TABELA 1 - Estimativas das variâncias (autovalores) associadas aos componentes principais relativos aos 15 caracteres estudados (NFP, NFP, NSF, MAD, COF, ALP, DPF, DIF, PMF, CFL, LFL, PMS, EPO, ARP, PSF) em 29 acessos de Capsicum spp. Campos dos Goytacazes: UENF, 2007.

\begin{tabular}{llll}
\hline CP' & Raiz & Raiz $(\%)$ & \% Acumulada \\
CP01 & 7,1547581 & 47,6983872 & 47,6983872 \\
CP02 & 3,6438760 & 24,2925065 & 71,9908937 \\
CP03 & 1,2658464 & 8,4389758 & 80,4298695 \\
CP04 & 0,9156747 & 6,1044980 & 86,5343675 \\
CP05 & 0,6034709 & 4,0231396 & 90,5575071 \\
CP06 & 0,5430878 & 3,6205854 & 94,1780925 \\
CP07 & 0,2918380 & 1,9455869 & 96,1236794 \\
CP08 & 0,2081160 & 1,3874397 & 97,5111191 \\
CP9 & 0,1440776 & 0,9605176 & 98,4716367 \\
CP10 & 0,1022340 & 0,6815600 & 99,1531968 \\
CP11 & 0,0561837 & 0,3745582 & 99,5277549 \\
CP12 & 0,0437270 & 0,2915134 & 99,8192684 \\
CP13 & 0,0158549 & 0,1056991 & 99,9249675 \\
CP14 & 0,0090970 & 0,0606465 & 99,9856140 \\
CP15 & 0,0021579 & 0,0143860 & 100,0 \\
\hline
\end{tabular}


BENTO, C. dos S. et al. Descritores Qualitativos...

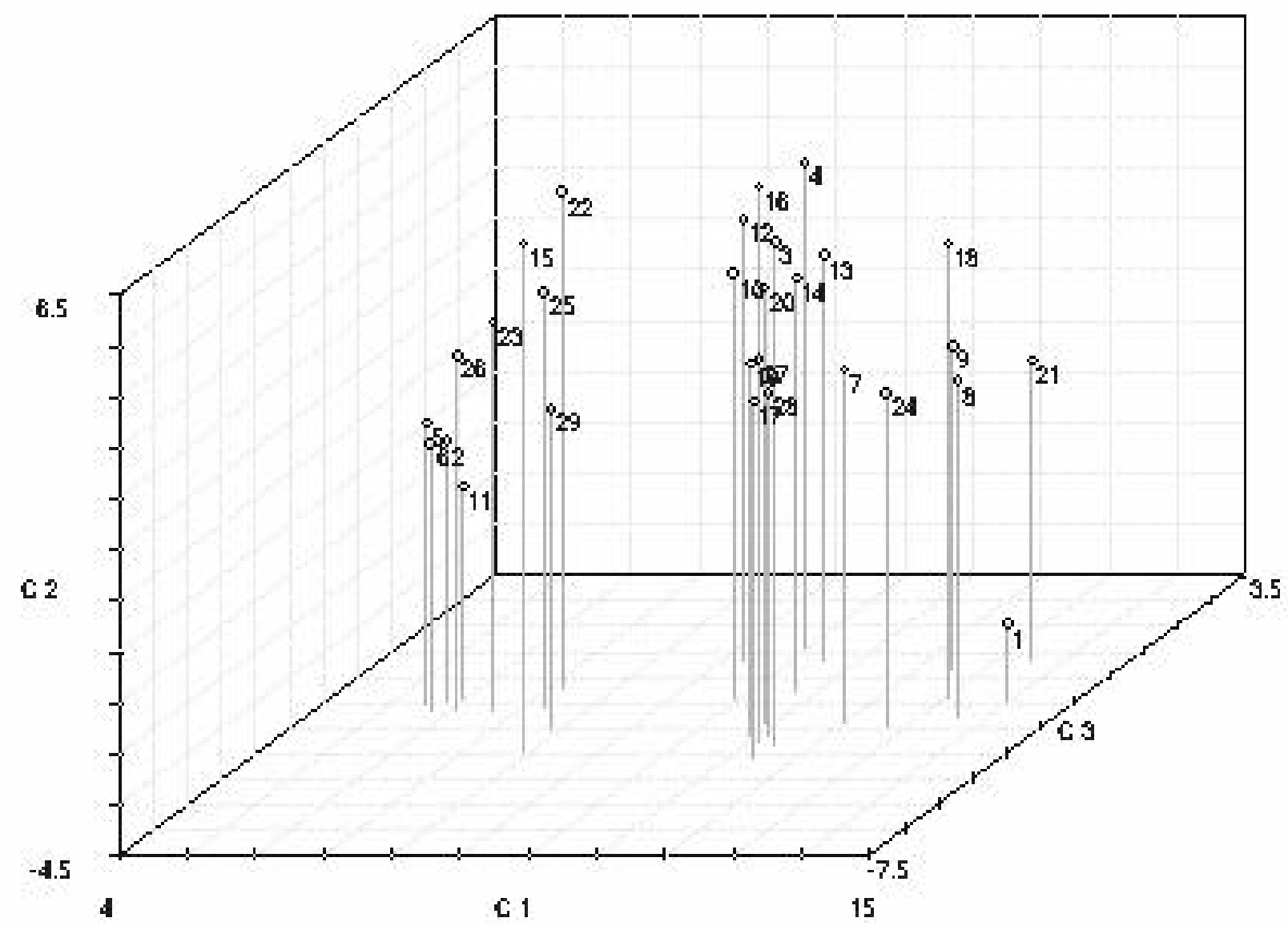

FIGURA 1 - Dispersão gráfica dos escores em relação aos eixos representativos dos três primeiros componentes principais (CP1, CP2 e CP3), de 15 caracteres morfoagronômicos, em 29 acessos de Capsicum spp. Campos dos Goytacazes: UENF, 2007. $1^{1}=$ UENF 1622; 2 = UENF 1623; 3 = UENF 1624; 4 = UENF 1625; 5 = UENF 1626; 6 = UENF 1627; 7 = UENF 1628; 8 = UENF 1629; 9 = UENF $1630 ; 10$ = UENF 1631; 11 = UENF 1632; 12 = UENF 1633; 13 = UENF 1634; 14 = UENF 1635; 15 = UENF 1636; 16 = UENF 1637; $17=$ UENF 1638; $18=$ UENF $1639 ; 19=$ UENF $1611 ; 20=$ UENF 1612; 21 = UENF 1613; 22 = UENF 1609; 23 = UENF 1640; 24 = UENF 1616; 25 = UENF $1618 ; 26$ = UENF 1641; 27 = UENF 1642; 28 = UENF 1643; 29 = UENF 1615.

Pelo método de SINGH (1981), utilizado para avaliar a importância relativa de 15 características quantitativas, determinou-se que sete destas características contribuíram com $98,31 \%$ para a divergência genética, enquanto oito contribuíram com apenas $1,69 \%$ (Tabela 2 ). Ao fazer o teste de descarte de variáveis pelo método de GARCIA (1998), utilizando a variável com menor contribuição para a diversidade entre os acessos (peso de sementes por fruto), verificou-se mudança na formação dos grupos, indicando que esta não deve ser descartada. Entretanto, ao retirar apenas a segunda variável com menor contribuição (área da copa da planta), não houve mudança no agrupamento, indicando que o descarte da mesma pode ser efetuado sem problemas. ABREU et al. (2004), trabalhando com feijão-de-vagem, observaram mudança no agrupamento apenas depois da eliminação de sete variáveis. Por sua vez, REGO et al. (2003), ao estudarem o gênero Capsicum verificaram a mesma formação de grupos, após retiradas separadamente as duas variáveis com menor contribuição. Contudo, ao retirá-las ao mesmo tempo observaram mudança no agrupamento. 
TABELA 2 - Contribuição relativa de 15 características quantitativas para a divergência genética entre 29 acessos de Capsicum spp., pelo método proposto por SINGH (1981). Campos dos Goytacazes: UENF, 2007.

\begin{tabular}{lcc}
\hline Variável $^{1}$ & Valor $(\%)$ & \\
NFP & 45,9943 & Valores acumulados (\%) $^{\circ}$ \\
NSF & 21,8816 & 45,9943 \\
MAD & 8,6246 & 67,8759 \\
COF & 8,0940 & 76,5005 \\
ALP & 6,0086 & 84,5945 \\
MED & 5,9606 & 90,6031 \\
DPF & 1,7424 & 96,5637 \\
DIF & 0,8572 & 98,3061 \\
PMF & 0,6579 & 99,1633 \\
CFL & 0,1349 & 99,8212 \\
LFL & 0,0206 & 99,9561 \\
PMS & 0,0142 & 99,9767 \\
EPO & 0,0054 & 99,9909 \\
ARP & 0,0024 & 99,9963 \\
PSF & 0,0012 & 99,9987 \\
\hline
\end{tabular}

1/NFP: número de frutos por planta; NSF: número de sementes por fruto; MAD: maior diâmetro de copa; COF: comprimento de fruto; ALP: altura de planta; MED: menor diâmetro da copa; DPF: dias para frutificação; DIF: diâmetro do fruto; PMF: peso médio de frutos; CFL: comprimento da folha; LFL: largura de folha; PMS: peso de 1000 sementes; EPO: espessura da polpa; ARP: área da copa da planta; PSF: peso de sementes por fruto.

A característica que mais contribuiu para a divergência genética foi o número de frutos por planta (NFP), com $46 \%$, e variação de 10 a 328 frutos por planta. Essa variável tem grande valor agronômico, principalmente quando associada ao peso e/ou tamanho do fruto. O peso médio do fruto (PMF), por sua vez, contribuiu pouco para a divergência, com cerca de $0,66 \%$, embora tenha apresentado grande variabilidade $(0,39 \mathrm{~g}$ a $50,12 \mathrm{~g})$.

Outra variável que teve significativa importância para o estudo da divergência foi o número de sementes por fruto (NSF), com 21,90\% de contribuição para a variabilidade entre os acessos. O NSF variou de 21 a 299, indicando que esse descritor deve ser levado em consideração na caracterização dos acessos, pois é de grande importância para a divergência genética entre estes.

O maior diâmetro de copa (MAD) foi a terceira característica que mais contribuiu para a divergência perfazendo 8,6\% (variação de 44,17 cm a $180 \mathrm{~cm}$ ). No manejo de bancos de germoplasma, sobretudo nas etapas de regeneração e multiplicação dos acessos, esse caráter auxilia na escolha de espaçamentos mais apropriados em função do diâmetro de copa de cada acesso. Por exemplo, quatro plantas com MAD de $44 \mathrm{~cm}$, como as do acesso UENF 1623, ocupam uma área aproximada de 1,0 $\mathrm{m}^{2}$, enquanto uma planta do acesso UENF 1639 (MAD de $1,80 \mathrm{~cm}$ de copa) ocupa uma área aproximada de $3,24 \mathrm{~m}^{2}$.

O comprimento de fruto (COF) variou de $10,24 \mathrm{~mm}$ a $143 \mathrm{~mm}$, contribuindo com 8,09\%, para a divergência genética entre os acessos. Em função dessa variável pode-se, determinar a forma de uso mais adequada para o acesso. Frutos pequenos, do tipo malagueta, como os do acesso UENF 1636, que obtiveram $2,2 \mathrm{~cm}$ de comprimento, têm maior potencial para serem comercializados em molhos industrializados, enquanto frutos grandes como os do acesso UENF 1622, com 14,3 cm de COF, podem ser comercializados, preferencialmente, "in natura" ou desidratados.

O descritor altura de planta (ALP) variou de $30 \mathrm{~cm}$ a $129 \mathrm{~cm}$, contribuindo com 6,0\% para a divergência entre os acessos. Para se determinar os tratos culturais de uma lavoura de pimenta ou pimentão é necessário saber, de antemão, a altura da planta, dado fundamental para determinar se há necessidade de tutoramento, tipo de tutor, necessidade de mão-de-obra e gasto com defensivos, uma vez que, quanto mais alta a planta e maior a sua copa, maior será a quantidade necessária de defensivos e horas por trabalhador.

Em estudos conduzidos com Capsicum, SUDRÉ et al.(2005) e TEIXEIRA (1996) verificaram que as características de maior importância para a divergência foram: comprimento e diâmetro do fruto, peso médio do fruto e peso de mil sementes, contrastando com os resultados encontrados no presente trabalho. Por outro lado, REGO et al. (2003), demonstraram que o número de sementes por fruto foi a segunda variável de maior importância para a variação em frutos de Capsicum, concordando com os dados aqui encontrados.

No dendrograma obtido pelo método de agrupamento do vizinho mais próximo (Figura 2), observou-se formação de dois grupos distintos, com distância genética de aproximadamente $68 \%$, sendo que um dos grupos ficou apenas com o acesso UENF 1622 e o outro com os 28 acessos restantes. O acesso UENF 1622 foi o que produziu o maior NSF alcançando a média de 299 sementes por fruto. Esse descritor foi o segundo mais importante para a discriminação dos acessos e talvez essa característica tenha sido a responsável por alocar o acesso UENF 1622, que teve um NSF muito superior aos outros em um grupo separado dos demais. 
BENTO, C. dos S. et al. Descritores Qualitativos...

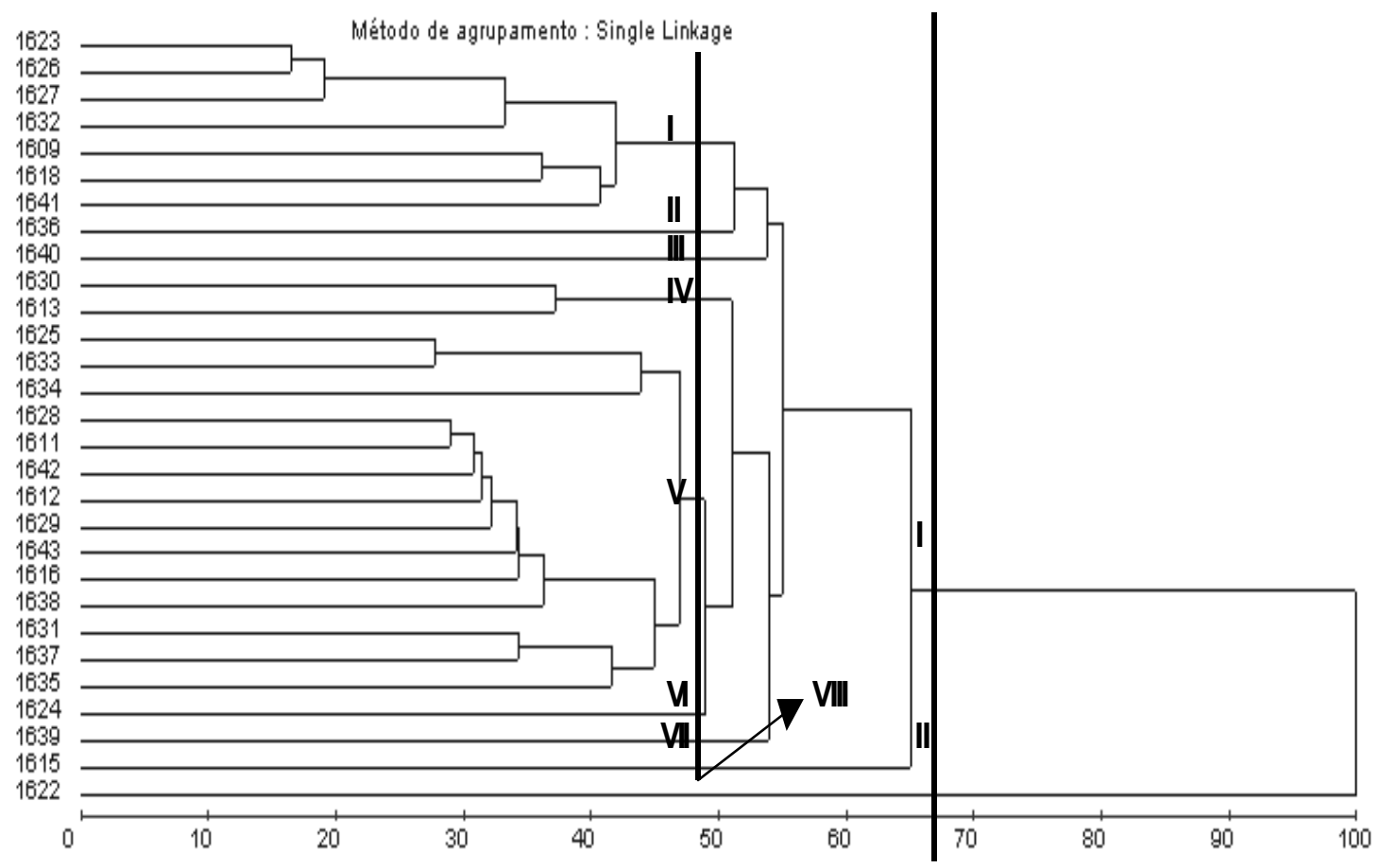

FIGURA 2 - Dendrograma de dissimilaridade genética (em percentagem) entre 29 acessos de Capsicum spp, obtido pelo método hierárquico do vizinho mais próximo, com base em 15 características morfoagronômicas. Campos dos Goytacazes: UENF, 2007.

Ao subdividir-se o grupo maior (grupo 1), fazendo-se um novo corte a $48 \%$, valor este escolhido devido a mudança abrupta no dendrograma e em concordância com o método de Tocher (CRUZ e REGAZZI, 2001), observou-se a formação de oito subgrupos. No subgrupo 1.1 ficaram os acessos UENF1623, UENF1626, UENF1627, UENF1632, UENF1609, UENF1618 e UENF1641, que se caracterizaram por possuírem plantas com baixo NSF (entre 21 a 62 sementes), MAD inferior a $112 \mathrm{~cm}$, COF entre $3,32 \mathrm{~cm}$ a $5,84 \mathrm{~cm}$ (médio a grande), a exceção do acesso UENF1609 que teve COF superior aos demais $(10,79 \mathrm{~cm})$, e ALP de $43 \mathrm{~cm}$ (plantas baixas). O NFP foi altamente variável entre os acessos desse grupo, fato este interessante, pois mostra que é possível se selecionar plantas baixas com maior produção de frutos de tamanho médio e com poucas sementes.

O subgrupo 1.2, formado apenas pelo acesso UENF1636, caracterizou-se por possuir plantas com grande número de frutos (252 frutos), baixo PMF (0,39 g), baixo NSF (21 sementes), polpa pouco espessa $(0,65 \mathrm{~mm})$, com menor diâmetro do fruto (DIF) $(0,55 \mathrm{~cm}), A L P$ de $111 \mathrm{~cm}$ e com copa relativamente grande $(131 \mathrm{~cm})$.

O subgrupo 1.3 foi constituído apenas pelo acesso UENF1640, o qual obteve valores baixos para NFP (70 frutos), PMF (1,28 g), COF $(10,24 \mathrm{~mm}) \mathrm{e}$ NSF (40 sementes), o que fez esse acesso isolar-se dos demais.

O subgrupo 1.4 foi formado pelos acessos UENF1630 e UENF1613, cujas características alcançaram valores muito semelhantes, sendo distinguidos por plantas de altura mediana, com grandes copas e baixo NFP (34 frutos), PMF de 22 $\mathrm{g}$, COF de $43 \mathrm{~cm}$ e grande NSF (165 sementes).

O subgrupo 1.5 foi composto pelos acessos UENF1625, UENF1633, UENF1634, UENF1628, UENF1611, UENF1642, UENF1612, UENF1629, UENF1643, UENF1616, UENF1638, UENF1631, UENF1637 e UENF1635, que obtiveram valores médios bem próximos para os descritores de maior divergência fenotípica, como NFP (110 frutos), NSF (79 sementes), MAD $(134 \mathrm{~cm})$, COF $(7 \mathrm{~cm})$ e ALP $(96 \mathrm{~cm})$. 
O subgrupo 1.6 constituiu-se do acesso UENF1624, com características bem distintas dos demais, tais como plantas altas (ALP de $129 \mathrm{~cm}$ ), copa extensa (MAD de $161 \mathrm{~cm}$ ), NFP (157 frutos) e frutos compridos (COF de 7,7 cm), que reunidas contribuíram para o isolamento desse acesso.

O subgrupo 1.7 foi constituído pelo acesso UENF1639, que revelou o maior diâmetro de copa $(180 \mathrm{~cm})$ e o terceiro maior NSF (149 sementes).

O subgrupo 1.8 foi representado apenas pelo acesso UENF1615, que denotou valores baixos para os descritores de maior divergência fenotípica, como NFP (21 frutos), NSF (52 sementes), COF $(4 \mathrm{~cm}$ ) e ALP $(47 \mathrm{~cm})$.

Utilizando-se o método de Tocher, com base nas variáveis quantitativas, os 29 acessos analisados foram divididos inicialmente em dois grupos (Tabela 3). No grupo I ficaram 27 acessos. Os dois acessos restantes ficaram no grupo II (UENF1622 e
UENF1613). Estes acessos destacaram-se dos demais por possuírem em média 299 e 190 sementes por fruto, respectivamente, sendo estes valores os maiores para esse descritor. Conforme já mencionado anteriormente, o descritor NSF foi considerado pelo método de Singh o segundo descritor que mais contribuiu para a divergência fenotípica. Observouse concordância parcial entre os métodos de agrupamento do vizinho mais próximo e o de Tocher, já que ambos separaram o acesso UENF 1622 dos demais. Entretanto, no método de Tocher o acesso UENF 1613 foi alocado juntamente com o acesso UENF 1622. Como houve concordância dos métodos em relação ao acesso UENF 1622, procedeu-se um novo agrupamento com a exclusão desse acesso para permitir uma nova comparação entre os métodos. Com este novo agrupamento sete grupos foram formados e verificou-se a concordância entre os métodos do vizinho mais próximo e Tocher.

TABELA 3 - Agrupamento de 29 acessos de Capsicum spp. formados pelo método de otimização de Tocher, com base em 15 caracteres quantitativos. Campos dos Goyatacazes: UENF, 2007.

\begin{tabular}{ll}
\hline Grupo & Acessos \\
\hline 1 & $1623,1626,1627,1632,1641,1618,1640,1609,1633,1631,1636,1637$, \\
& $1612,1611,1635,1642,1643,1628,1634,1638,1615,1625,1624,1616$, \\
& $1629,1630,1639$, \\
\hline 2 & 1622,1613, \\
\hline
\end{tabular}

Uma comparação entre os grupos formados pelos métodos de Tocher e do vizinho mais próximo permitiu inferir que os resultados obtidos por esses dois métodos foram parcialmente concordantes, uma vez que alguns acessos foram classificados em grupos diferentes.

O grupo I de Tocher foi semelhante ao subgrupo 1.1 do vizinho mais próximo (Figura 2), diferindo apenas por não conter o acesso UENF 1609. O grupo II, obtido pelo método de Tocher, conteve o maior número de acessos e foi semelhante ao subgrupo 1.6 do vizinho mais próximo. Os acessos UENF 1625, UENF 1633 e UENF 1634 formaram o subgrupo 1.5 e o acesso UENF 1624 formou o subgrupo 1.7 no vizinho mais próximo. O grupo III conteve os acessos UENF 1629 e UENF 1616, que no vizinho mais próximo ficaram inseridos no subgrupo 1.6. O grupo IV foi idêntico ao subgrupo
1.4 do vizinho mais próximo. O grupo $\mathrm{V}$ abrangeu os acessos UENF 1636 e UENF 1609, sendo que no vizinho mais próximo o primeiro acesso formou o subgrupo 1.2, com apenas este acesso, e o último ficou contido no subgrupo 1.1. O grupo VI foi formado pelos acessos UENF 1640 e UENF 1615, em que o primeiro acesso formou o subgrupo 1.3 e o segundo ficou no subgrupo 1.6 do vizinho mais próximo. O último grupo (VII) conteve apenas o acesso UENF 1639 , o qual também formou sozinho o subgrupo 1.8 do vizinho mais próximo.

A análise multicategórica realizada com 28 acessos permitiu a formação de sete grupos (Tabela 4) pelo método de Tocher. SUDRÉ et al. (2006) ao estudarem a divergência fenotípica entre 59 acessos de Capsicum utilizando 15 descritores qualitativos, obtiveram a formação de oito grupos pelo método de Tocher.

TABELA 4 - Agrupamento de 28 acessos de Capsicum spp. formados pelo método de otimização de Tocher para caracteres qualitativos. Campos dos Goytacazes: UENF, 2007.

\begin{tabular}{cl}
\hline Grupo & Acessos \\
I & $1611,1612,1638,1624,1628,1642,1633,1639,1631,1613,1637,1635,1630,1625,1623$ \\
II & $1626,1627,1632$ \\
III & $1609,1640,1634,1618$ \\
IV & 1629,1616 \\
V & 1641,1615 \\
VI & 1636 \\
VII & 1622 \\
\hline
\end{tabular}


BENTO, C. dos S. et al. Descritores Qualitativos...

As variáveis multicategóricas têm a vantagem de serem, características de fácil observação e que requerem menos tempo e mãode-obra, sendo a sua utilização ideal em bancos e coleções que não dispõem de muitos recursos humanos e financeiros.

Os resultados obtidos das análises multivariadas utilizando dados quantitativos e qualitativos foram parcialmente concordantes quanto ao agrupamento dos acessos trabalhados.

\section{CONCLUSÕES}

Houve divergência fenotípica entre os 29 acessos estudados, demonstrando o potencial que os acessos têm para uso em programas de melhoramento.

As características que mais contribuíram para a divergência entre os acessos foram o número de frutos por planta (NFP), o número de sementes por fruto (NSF), o maior diâmetro de copa (MAD) e o comprimento da folha (CFL).

Os métodos de agrupamento de Tocher e do vizinho mais próximo foram parcialmente concordantes na separação dos acessos, permitindo agrupar igualmente pelos dois métodos 19 dos 28 acessos analisados.

A análise de variáveis multicategóricas se mostrou eficiente no agrupamento dos acessos de pimenta estudados, indicando que seu emprego na quantificação da divergência fenotípica e na identificação de grupos heteróticos, pode auxiliar no manejo do banco de germoplasma e na seleção de acessos para programas de melhoramento genético.

\section{REFERÊNCIAS}

1. ABREU, F.B.; LEAL, N.R.; RODRIGUES, R.; AMARAL JUNIOR, A.T.; SILVA, D.J.H. Divergência genética entre acessos de

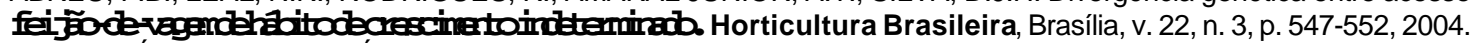

2. AMARAL JÚNIOR, A.T. do; THIÉBAUT, J.T. de L. Análise multivariada na avaliação da diversidade em recursos genéticos vegetais . Campos dos Goytacazes: UENF, 1999. 55 p.

3. BUENO, L.C. de S.; MENDES, A.N.G.; CARVALHO, S.P. Melhoramento genético de plantas : princípios e procedimentos. Lavras: UFLA, 2001.282 p.

4. CARVALHO, S.I.C.; BIANCHETTI, L.B.; BUSTAMANTE, P.G.; SILVA, D.B. Catálogo de germoplasma de pimentas e pimentões (Capsicum spp.) da Embrapa Hortaliças. Brasília: Embrapa Hortaliças, 2003. 49 p.

5. COSTA, F.R; PEREIRA, T.N.S.; VITÓRIA, A.P.; CAMPOS, K.P.; RODRIGUES, R.; da SILVA, D.H.; PEREIRA, M.G. Genetic diversity among Capsicum accessions using RAPD markers. Crop Breeding and Applied Biotechnology, Viçosa, v. 6, n. 1, p. 18-23, 2006.

6. CRUZ, C.D. Programa Genes (versão Windows); aplicativo computacional em genética e estatística. Viçosa: UFV, 2006. 175 p.

7. CRUZ, C.D.; REGAZZI, A.J. Modelos biométricos aplicados ao melhoramento genético. 2. ed. Viçosa: UFV, 2001.390 p.

8. GARCIA, S.L.R. Importância de características de crescimento, de qualidade da madeira e da polpa na diversidade genética de clones de eucalipto. Viçosa, 1998. 103 f. Dissertação (Mestrado) - Universidade Federal de Viçosa.

9. IPGRI. Descriptores para Capsicum (Capsicum spp). Roma: IPGRI, 1995.51 p.

10. MARTINELLO, G.E.; LEAL, N.R.; AMARAL JÚNIOR, A.T.; PEREIRA, M.G.; DAHER, R.F. Diversidade genética em quiabeiro baseada em marcadores RAPD. Horticultura Brasileira, Brasília, v. 21, n. 1, p. 20-25, 2003.

11. NASS, L.L.; PATERNIANI, E. Pré-breeding: a link between genetic resources and maize breeding. Scientia Agricola, Piracicaba, v. 57, n. 3, p. 581-587, 2000.

12. RAMOS, S.R.R. Genetic diversity based on AFLP markers and indicators for the establishment of a core collection for pumpking (Cucurbita moschata) for north-east Brazil. Plant Genetic Resources Newsletter, Maccarese (Fiumicino), Italy, v. 145, p. 66, 2006.

13. REGO, E.R. do; REGO, M.M. do; CRUZ, C.D.; CECON, P.R.; AMARAL, D.S.S.L.; FINGER, F. Genetic diversity analysis of peppers: a comparison of discarding variable methods. Crop Breeding and Applied Biotechnology, Viçosa, v. 3, n. 1, p. 1926, 2003.

14. RODRIGUEZ, J.M.; BERKE, T.; ENGLE, L.; NIENHUIS, J. Variation among and within Capsicum species revealed by RAPD markers. Theoretical and Applied Genetics, Berlin, v. 99, p. 147-156, 1999.

15. SCHUELTER, A.R. Análise isozimática, dialélica e diversidade genética da pimenta silvestre (Capsicum flexuosum Sendt.). Viçosa: 1996. 80 f. Dissertação (Mestrado em Genética e Melhoramento) - Universidade Federal de Viçosa.

16. SINGH, D. The relative importance of characters affecting genetic divergence. The Indian Journal of Genetic and Plant Breeding, New Delhi, v. 41, p. 237-245, 1981.

17. SUDRÉ, C.P., RODRIGUES, R., RIVA, E.M., KARASAWA, M., AMARAL JUNIOR, A.T. Divergência genética entre acessos de pimenta e pimentão utilizando técnicas multivariadas. Horticultura Brasileira, Brasília, v. 23, n. 1, p. 22-27, 2005.

18. SUDRÉ, C.P., CRUZ, C.D., RODRIGUES, R., RIVA, E.M., AMARAL JUNIOR, A.T., SILVA, D.J.H., PEREIRA, T.N.S. Variáveis multicategóricas na determinação da divergência genética entre acessos de pimenta e pimentão. Horticultura Brasileira, Brasília, v. 24, n. 1, p. 88-93, 2006.

19. TEIXEIRA, R. Diversidade em Capsicum: análise molecular, morfoagronômica e química. Viçosa, 1996. 81 f. Dissertação (Mestrado em Genética e Melhoramento) - Universidade Federal de Viçosa.

20. VALLS, J.F.M Caracterização morfológica, reprodutiva e bioquímica de germoplasma vegetal. In: ENCONTRO SOBRE RECURSOS GENÉTICOS. Anais . Jaboticabal: FCAV, 1988. p.106-120. 